ISSN 1676-3742

\title{
Maria no Vaticano II: renovação na Mariologia
}

\author{
Mary at Vatican II: renewal of Mariology
}

\author{
Pedro K. Iwashita CSSp.
}

\section{Resumo}

À luz da Revelação bíblica e do mistério pascal de Jesus, o Concílio contempla Maria como figura exemplar da Igreja, modelo de fé, esperança e caridade. De um lado, nela resplandece a graça que restaura na humanidade a imago Dei; de outro, nela antevemos a glória que nos aguarda, como remidos no Senhor. Nesta perspectiva, o Concílio propõe uma mariologia bíblica e eclesial, com novas luzes para o culto e a espiritualidade, através então de um retorno às fontes bíblicas e patrísticas, e de abertura maior ao mundo; integração maior da mariologia no conjunto da teologia, de modo que Maria possa ser vista no conjunto da história da salvação, em íntima associação à obra redentora do seu Filho e uma releitura da mariologia conforme o critério bíblico, antropológico, ecumênico e pastoral.

Palavras-chave: Maria; Culto; Vaticano II, Lumen Gentium 8.

\section{Abstract}

In the light of biblical revelation and the paschal mystery of Jesus, the council contemplates Mary as exemplar of the Church, model of faith, hope and charity. On one hand, it shines the grace that restores humanity in the imago Dei; otherwise, it anticipates the glory that awaits us, as redeemed in the Lord. Accordingly, the Council proposes a biblical and ecclesial Mariology, with new lights for cult and spirituality, then through a U-turn on the biblical and patristic sources, and greater openness to the world; greater integration of 
Mariology in the whole of theology, so that Mary can be seen throughout the history of salvation, in close association with the redemptive work of her Son Jesus, a reinterpretation of Mariology according to a biblical, anthropological, ecumenical and pastoral criteria.

Keywords: Mary; Cult; Vatican II, Lumen Gentium 8.

\section{Introdução}

O Concílio Vaticano II possibilitou uma retomada da mariologia à luz da revelação bíblica, do mistério pascal e também com base na patrística e na teologia contemporânea.

Foi a primeira vez na história que um Concílio se manifestou de uma maneira tão explícita e ampla sobre a Mãe do Salvador': "O Concílio Vaticano II, celebrado pela igreja católica com a presença de quase todos os seus pastores e com a participação de representantes das várias igreja separadas, pode ser considerado o concílio ecumênico que difundiu o documento doutrinal mais significativo e orgânico sobre a bem-aventurada virgem Maria: o capítulo VIII da constituição dogmática sobre a Igreja, Lumen gentium"2.

As repetidas críticas dirigidas à mariologia haviam produzido, nos anos 60, uma moratória dos tratados de mariologia, em que se juntam somente as elaborações de obras aparecidas anteriormente ao Vaticano II. ${ }^{3}$ Contestou-se nos tratados as orientações unilaterais e triunfalísticas da mariologia dos manuais; certo isolamento dentro do conjunto da dogmática, como se fosse uma ciência independente; sistematização rígida demais centrada na divisa: "Ad Jesum per Mariam"; mas a contestação mais decisiva veio da área protestante, que viu na mariologia um desvio fatal do Evangelho original sob a pressão popular e, em consequência, de um sincretismo entre a fé e a mitologia. ${ }^{4}$

Segundo João Batista Libanio, mais que uma batalha teológica, tratou-se de uma batalha simbólica, esbarrando em uma barreira afetiva. "Depois da proclamação dos dogmas marianos nos séculos XIX e XX, a devoção popular

\footnotetext{
${ }^{1}$ Cf. DE FIORES, Stefano, in: Nuovo Dizionario di Mariologia (NDM), Roma: Paulinas, 1985, 891. ${ }^{2}$ MEO, S. Verbete: Concílio Vaticano II. In: DE FIORES, S.; MEO S. (Org.). Dicionário de Mariologia. São Paulo: Paulus, 1995, p. 296.

${ }^{3}$ Cf. DE FIORES, Stefano, in: Nuovo Dizionario di Mariologia, 893.

${ }^{4}$ DE FIORES, Stefano, in: Nuovo Dizionario di Mariologia (NDM), Roma: Paulinas, 1985, 892-893.
} 
mariana atingira níveis bem elevados. A tradição protestante é muito sóbria em relação à mariologia. Houve por parte das confissões evangélicas, teologicamente consistentes, uma reformulação positiva em relação ao culto de Maria, embora denominações pentecostais e neopentecostais mais recentemente reajam contra a devoção mariana de maneira apaixonada. E, às vezes, os dois lados em oposição se extremam em suas atitudes". ${ }^{5}$

Essas contestações vieram acompanhadas de um desejo de retorno às fontes bíblicas e patrísticas, e de abertura maior ao mundo; integração maior da mariologia no conjunto da teologia, de modo que Maria pudesse ser vista no conjunto da história da salvação, em íntima associação à obra redentora do seu Filho Jesus, sob a divisa: "Ad Mariam per Jesum"6 e uma releitura da mariologia conforme o critério bíblico, antropológico, ecumênico e pastoral (LG 55-59).7

Critério bíblico - o Concílio procurou ser fiel à Sagrada Escritura, assim como ela é lida e interpretada pela Igreja, mas também como foi lida pelos Padres e doutores, sendo esse então o critério fundamental que orientou o Concílio na elaboração de sua doutrina sobre Maria. ${ }^{8}$ "Ao descrever a figura, a missão, o significado de Maria na história da salvação, não baseia a sua exposição em arbitrárias interpretações exegéticas de algum texto bíblico isolado para provar aprioristicamente formulações de fé, ou em um conjunto de lugares bíblicos para elaborar especulativamente um tratado de mariologia, mas atém-se a uma releitura global e ordenada de toda a sagrada Escritura, do AT ao NT, utilizando os critérios hermenêuticos mais seguros oferecidos pela exegese patrística e pelos estudos atuais. O nosso texto, na sua exposição, prende-se mais à Maria bíblica do que à Maria do dogma ou da teologia sistemática"9.

Critério antropológico - procura-se enfatizar o valor da pessoa humana na realização da história da salvação e diante da vontade de Deus, e que o homem não seja considerado mero objeto de salvação da parte de Deus, mas também como sujeito, que embora como criatura, é capaz de cooperar com ele. Em relação a Maria, esse critério permite dar maior evidência aos valores pessoais expressos por Maria na sua vida histórica, como também ressalta

${ }^{5}$ LIBANIO, João Batista. Concílio Vaticano II. Em busca de uma primeira compreensão. São Paulo: Loyola, 2005, p. 142.

${ }^{6}$ DE FIORES, Stefano, in: Nuovo Dizionario di Mariologia, 892-893.

${ }^{7}$ Cf. MEO, S. Verbete: Concílio Vaticano II. In: DE FIORES S.; MEO S. (Org.). Dicionário de Mariologia. São Paulo: Paulus, 1995, pp. 300-301.

${ }^{8}$ Ibidem, p. 300.

${ }^{9}$ MEO, S. Verbete: Concílio Vaticano II. In: DE FIORES S.; MEO S. (Org.). Dicionário de Mariologia. São Paulo: Paulus, 1995, p. 300. 
a riqueza de sua experiência cristã e o testemunho de uma vida vivida na obscuridade dos acontecimentos e das dores, de sua obediência a Deus, de sua esperança e caridade, a sua disponibilidade em cooperar, de forma livre, consciente e responsável em relação à pessoa e à obra de Cristo. ${ }^{10}$

Critério ecumênico - representou uma das maiores preocupações do Concílio Vaticano II, no sentido de iniciar um diálogo com o mundo protestante, preocupação essa que esteve presente na elaboração de todos os documentos conciliares, e teve particular importância na preparação do texto sobre a Virgem Maria, no Cap. VIII da Lumen Gentium, porque o problema mariano constitui um ponto de divergência entre as diferentes confissões cristãs. Para isso o Concílio, no que se refere à doutrina marial, procurou se ater essencialmente às indicações da Sagrada Escritura, tal como é lida na Igreja, através de uma exegese rigorosa, com o objetivo de purificar a apresentação do mistério de Maria, para que a Mãe de Deus e dos homens seja não um ponto de divisão, mas de convergência e de unidade de todos os irmãos de Cristo. ${ }^{11}$

Critério pastoral - o Vaticano II foi um concílio essencialmente pastoral e como tal não foi intenção do concílio, na formulação da doutrina mariana, proclamar nenhum dogma novo, mas expor uma doutrina mais eficazmente pastoral. Neste sentido Maria é apresentada na Lumen Gentium como pessoa para ser compreendida, amada, venerada e imitada, dentro das linhas bíblicas, o que permitiu a apresentação de uma doutrina mariana mais concreta e acessível a todos, possibilitando também uma renovação também cultural da Igreja. ${ }^{12}$

\section{O debate que antecedeu a realização do Vaticano II}

A realização do Congresso Mariológico de Lourdes em 1958 foi o momento em que se confrontaram duas tendências da Mariologia na época, a tendência cristotípica e a tendência eclesiotípica, que se apresentaram como caminhos exclusivos. Mas, na verdade, essas tendências procuravam caracterizar o modo como era concebida a cooperação de Maria na obra da salvação, tema ligado também ao da corredenção, ou participação de Maria na obra redentora.

Esta polarização implicou no desaparecimento de outra posição muito mais reticente e minimalista na maneira de conceber a cooperação de Maria na obra da salvação.

\footnotetext{
${ }^{10}$ Ibidem, p. 300.

${ }^{11}$ Ibidem, p. 300.

${ }^{12}$ Ibidem, p. 301.
} 
H. Lennerz, representante mais conhecido desta posição, não admitia cooperação de Maria à obra que o Cristo realizou nos adquirindo as graças através de sua Encarnação, para a qual ela contribuiu dizendo o seu sim, sendo esta, portanto, a sua contribuição para a nossa redenção.

Através da Encarnação o Cristo ao receber a natureza humana, se tornou capaz de morrer por nós, o que propriamente constituiu a redenção. ${ }^{13}$

A posição de H. Lennerz representava na verdade a tendência eclesiotípica da Mariologia, que não admitia cooperação de Maria à obra pela qual Cristo nos adquiriu as graças mais que aquelas contidas na Encarnação em si, e essa cooperação, mesmo sendo formal, seria mediada e de ordem física, pois o sim de Maria tornou possível a Encarnação, que é prévia à Redenção. O que Maria deu a Cristo é uma realidade física, a natureza humana, engendrando a seu filho.

A crítica que se fez a Lennerz, é que a sua concepção de redenção era pobre, quase reduzindo a Redenção à morte de Cristo na cruz, mas a Encarnação não é somente prévia à Redenção, é ela mesma salvadora, e a teoria de Lennerz teria que ser superada não somente por razões mariológicas, mas também para o progresso mesmo da Cristologia moderna, que recusa ver na Encarnação somente algo prévio à Redenção, mas como sendo intrínseco à mesma. ${ }^{14}$

De outro lado, a tendência eclesiotipica também foi questionada como contendo elementos artificiais, pois se questionou, por que é necessário o sim de Maria junto à cruz, dado em nome da Igreja, prévio às respostas dos indivíduos, para que o sim dos mesmos implique na incorporação à Igreja. Não bastaria o fato objetivo de que a humanidade de Cristo é cabeça do Corpo Místico, começo do organismo de salvação para que o sim individual de cada indivíduo, sem necessidade de um sim prévio representativo da Igreja em vista da incorporação em Cristo a esse organismo que é a Igreja? Não se estaria diminuindo nesta explicação a importância objetiva da humanidade de Cristo enquanto fundamento da realidade da Igreja?

A solução proposta por Juan Alfaro após o encerramento do Congresso de Lourdes, evita elementos de artificialidade especulativa, é independente das duas tendências da Mariologia. Acentua a importância do sim de Maria na Anunciação, interpretando-o como colaboração imediata à obra da Redenção.

O sim de Maria não é somente um sim para que Cristo seja engendrado em seu seio, mas também a aceitação para unir sua vida, suas alegrias e suas

${ }^{13}$ Cf. POZO, Cándido SJ. María, nueva Eva. Madrid: BAC, 2005, pp. 18-19.

${ }^{14}$ Ibidem, p. 22. 
dores à vida, alegria e dores de seu Filho, sem esquecer que a Anunciação contém uma primeira descrição programática disso, o que atribui um novo valor de responsabilidade moral e consciência ao sim de Maria.

Esse sim que ela vai manter ao longo de sua vida, principalmente na hora suprema da prova junto à cruz em que morre seu Filho. ${ }^{15}$

Aqui se trata da manutenção de um sim já dado, que tem valor não distinto da aceitação mesma da Encarnação, dado que a aceitação da Encarnação é cooperação imediata à obra da salvação, também o é sua manutenção junto à Cruz. ${ }^{16}$ Desta forma o caminho estava preparado para a renovação que veio com o Concílio Vaticano II.

\section{Uma nova orientação da Mariologia}

Esse desejo de renovação começa a se tornar realidade pelo impulso dado pelo Vaticano II. Haja vista que, embora a moratória dos tratados de mariologia nos anos 60 tenha continuado no decênio que se seguiu, introduziu-se já corretivo importante, com a inserção do tratado mariológico na cristologia e na eclesiologia. ${ }^{17}$ Preconizou-se assim, "uma 'reentrada' da mariologia na teologia da qual se tinha destacado por exigência de organicidade e o fim de um discurso mariano separado, com as desvantagens do isolamento, perda do sentido da globalidade, polarização sobre Maria e desenvolvimento unidimensional". ${ }^{18}$ A mariologia passou a se beneficiar de contribuições de vários setores da teologia, emergindo como tratado sobre Maria, mas numa síntese dos dados adquiridos na reflexão global, sem a pretensão de organicidade autônoma, e renovação estética e experiencial sobre as vias histórico-salvíficas. ${ }^{19}$

\footnotetext{
${ }^{15}$ J. Alfaro, "Significatio Mariae in Mysterio Salutis", 22-23, apud POZO, Candido. María, nueva Eva, p. 25.

${ }^{16}$ Cf. POZO, Candido. María, nueva Eva, p. 25.

${ }^{17}$ É o que se tentou fazer na coleção "Mysterium Salutis". Cf. MÜLLER, 1969, Marias Stellung und Mitwirkung im Christusereignis“, in Mysterium Salutis III/2, 393-510.

${ }^{18}$ DE FIORES, in Nuovo Dizionario di Mariologia, Roma: Paulinas, 1985, 893.

${ }^{19}$ Ibidem, 893. E nessa linha que saíram, nos últimos anos, as obras de Candido Pozo, Maria en la obra de la salvación, Madrid, 1974; de Leonardo BOFF, O rosto materno de Deus, Petrópolis, 1979. Convém anotar ainda que, na linha da renovação, saíram os livros de: MÜLLER, 1980, Glaubensrede über die Mutter Jesu. Versuch einer Mariologie in heutiger Perspektive, Mainz; BEINERT-PETRI, 1984 (org.), Handbuch der Marienkunde, Regensburg; o dicionário organizado por DE FIORES-MEO, 1985, Nuovo Dizionario di Mariologia (NDM), Turim, que é certamente um marco na história da mariologia, dentro de uma perspectiva de renovação.
} 
Porém é preciso lembrar, que além dos debates teológicos que precederam o evento do Vaticano II, “é necessário termos presentes o valor histórico da definição dogmática da assunção de Maria, proclamada por Pio XII em 1950. Ela conclui o caminho percorrido no último século pelos estudos teológicos sobre Maria - os quais abrangem o privilégio da imaculada conceição, a dupla missão de Maria: mediação universal de todas as graças e cooperação na redenção realizada por Cristo, e, enfim, o privilégio da assunção -, pelas intervenções cada vez mais frequentes do magistério pontifício e pela difusão cada vez mais viva e sentida do culto mariano, tanto litúrgico quanto devocional". ${ }^{20}$

O Concílio Vaticano II não proclamou nenhum dogma mariano novo, porém é importante que o Concílio retomou, endossou e confirmou todas as proclamações dogmáticas referentes a Maria: Maria, Mãe de Deus (Concílio de Éfeso, 431, DH 250-251); Virgindade Perpétua de Maria (Concílio Lateranense, 649, DH 501-509); Imaculada Conceição (Pio IX, 8 de dezembro de 1854, Bula Ineffabilis, DH 2803-2804); Assunção de Maria (Pio XII, Const. Apost. Munificentissimus, $1^{\circ}$ de novembro de 1950, AAS 42(1950), DH 3900-3904).

\section{Uma explicitação maior do dogma da maternidade divina de Maria: Maria Mãe de Deus e Mãe da Igreja}

De outro lado, o Concílio Vaticano II contribuiu também para uma explicitação maior do dogma marial, a sua relação íntima com o mistério salvífico em Cristo, e a sua relação com a Igreja. Além disso, a doutrina mariológica do Vaticano II, cristalizada no capítulo VIII da Constituição dogmática Lumen Gentium, ${ }^{2 l}$ não foi somente um texto de compromisso entre a

\footnotetext{
Menciono ainda o livro de Ivone GEBARA e Maria Clara L. BINGEMER, Maria, Mãe de Deus e Mãe dos Pobres. Um ensaio a partir da mulher e da América Latina, Petrópolis, 1987. Mais recentemente foram publicadas as obras de BOFF, Clodovis. Mariologia Social. O significado da Virgem para a Sociedade. São Paulo: Paulus, 2006, PAREDES, José Cristo Rey García. Mariologia. Síntese bíblica, histórica e sistemática. São Paulo: Ave Maria, 2011 e, MURAD, Afonso. Maria toda de Deus e tão humana. Compêndio de Mariologia. São Paulo/Aparecida: Paulinas/Santuário, 2012.

${ }^{20}$ MEO, S. Verbete: “Concílio Vaticano II”. In: Dicionário de Mariologia. São Paulo: Paulus, 1995, p. 297.

${ }^{21}$ Cf. Literatura concernente: DE FIORES, 1984,3a ed., Maria nel mistero di Cristo e della Chiesa, Roma; LAURENTIN, 1967 e, Mutter Jesu - Mutter der Menschen. Zum Verständnis der marianischen Lehre nach dem Konzil, Limburg; SEMMELROTH, 1986, "Die selige jungfräuliche Gottesmutter Maria im Geheimnis Christi und der Kirche", in Lexikon für Theologie und Kirche (LThK) (Sonderausgabe) XII, 326-347, Freiburg i. Breisgau: Herder.
} 
tendência cristotípica e eclesiotípica na mariologia, ${ }^{22}$ tendência essa já existente entre os teólogos da década dos anos 60, e que teve seus ecos entre os Padres conciliares; ${ }^{23}$ longe de ser mero compromisso entre as tendências, foi, sim, no dizer de Cándido Pozo, uma espécie de denominador comum, ${ }^{24}$ o essencial de doutrina mariológica. Foi de vital importância que esse denominador comum tenha sido determinado, pois isso veio permitir a Paulo VI proclamar solenemente, no encerramento dos trabalhos da terceira etapa conciliar a 21 novembro de 1964, Maria Santíssima, MÃE DA IGREJA. ${ }^{25}$ Cándido Pozo pensa que o discurso de Paulo VI e a respectiva proclamação de Maria Mãe da Igreja, significou um estancamento das duas tendências, a cristológica e a eclesiológica, ${ }^{26}$ possibilitando à mariologia novo encaminhamento, pois a proclamação fora realizada certamente por motivos doutrinais, ${ }^{27}$ e não teria sido simples "ato de piedade meridional sem grande alcance teológico ou doutrinal", termos em que E. Schillebeeckx julgou a proclamação pontifical. ${ }^{28}$ Embora o título Maria, Mãe da Igreja não esteja presente na doutrina do cap. VIII, deve ser considerado ato do Vaticano II, já que o discurso de Paulo VI, mesmo sem fazer parte do cap. VIII, tem que ser encarado como ato do Concílio. ${ }^{29}$

Com efeito, Paulo VI recolhe, na sua proclamação, dois grandes temas patrísticos, a saber, o paralelismo Maria e Igreja, mas também o da transcendência de Maria com respeito à Igreja, uma vez que o título "Mãe da Igreja",

${ }^{22}$ Cf. POZO, Cándido, Maria en la obra de la salvación, Madrid: BAC, 1974,51-56.

${ }^{23}$ Ibidem, 23-31.

${ }^{24}$ Cf. POZO, Cándido, Maria en la obra de la salvación, Madrid: BAC, 1974, 56: "Mais que uma superação das duas tendências, o Concilio nos oferece - se nos é lícito falar deste modo - seu mínimo denominador comum. Confiamos que não se dê a estas palavras um sentido pejorativo; tal mínimo denominador comum é o núcleo da doutrina católica, comum às duas tendências mariológicas".

${ }^{25}$ MS 56 (1964),1015. Cf. tb. Documentation Catholique (DC) 6/12/1964,1544: "É então para a sua glória e para o nosso consolo que nós proclamamos a Santíssima Virgem Maria MÃE DA IGREJA, isto é, de todo o povo de Deus, tanto dos fiéis como dos pastores, que nós a chamamos Mãe muito amada; e desejamos que, doravante, com este título tão suave, a Virgem seja ainda mais honrada e invocada por todo o povo cristão".

${ }^{26}$ Cf. POZO, C., María en la obra de la salvación, Madrid: BAC, 1974, 59.

27 Ibidem, 59: "O papa procedeu à proclamação por razões doutrinais". Cf. tb. René LAURENTIN, in EtMar22, 1965, p.21: "Paulo VI fez este ato por razões doutrinais que dependem de seu magistério".

${ }^{28}$ SCHILLEBEECKX, E., L'Église du Christ et l'homme d'aujourd'hui selon Vatican II, 164s., Paris, 1965, apud POZO, C., op. cit., 59.

${ }^{29}$ Cf. MEO, S. Verbete: Concílio Vaticano II. In: DE FIORES S.; MEO S. (Org.). Dicionário de Mariologia. São Paulo: Paulus, 1995, p. 298. 
enquanto afirmação de transcendência de Maria com respeito à Igreja, já aparece no século II, ${ }^{30}$ fatos esses que vêm significar que o mistério de Maria é mistério complexo, não abarcado suficientemente pelas polarizações cristológicas ou eclesiológicas, assinalando-nos assim o caminho futuro da mariologia. ${ }^{31}$

\section{Uma explicitação maior do Dogma da Imaculada Conceição}

Em relação ao dogma da Imaculada Conceição, o Concílio Vaticano II, permanece fiel aos termos da proclamação oficial na bula Ineffabilis de Pio IX, declarando explicitamente que a Virgem foi preservada e foi imune de toda mancha da culpa original. ${ }^{32}$ Porém na justificação, além de apresentar os fundamentos apresentados por Pio IX, o documento conciliar explicita as bases do dogma, deixando mais claro ainda que a imaculada conceição tem a ver com a íntima associação de Maria com o Redentor, o seu Filho Jesus Cristo, associação na obra salvífica, associação na sua maternidade divina, e para tudo isso foi moldada pelo Espírito Santo. Nesse sentido é importante o $\mathrm{n}^{\mathrm{o}} 56$ da Lumen Gentium:

Quis, porém, o Pai das misericórdias que a encarnação fosse precedida pela aceitação daquela que era predestinada a ser Mãe de seu Filho, para que assim como a mulher contribuiu para a morte, a mulher também contribuísse para a vida, O que de modo excelentíssimo vale da Mãe de Jesus, a qual deu ao mundo a própria Vida que tudo renova e foi por Deus enriquecida com dons dignos para tamanha função. Daí não admira que nos Santos Padres prevalecesse o costume de chamar a Mãe de Deus toda santa, imune de toda mancha de pecado, como plasmada pelo Espírito Santo e formada nova criatura. Dotada desde o primeiro instante de sua conceição dos esplendores de uma santidade inteiramente singular, a Virgem de Nazaré é por ordem de Deus saudada pelo Anjo anunciador como "cheia de graça" (Lc 1,28). E ela mesma responde ao mensageiro celeste: "Eis aqui a serva do Senhor, faça-se em mim segundo a tua palavra" (Lc 1,38). Assim Maria, filha de Adão, consentindo na palavra divina, se fez Mãe de Jesus. E abraçando a vontade salvífica de Deus com coração pleno, não retida por nenhum pecado, consagrou-se totalmente como

\footnotetext{
${ }^{30}$ Cf. POZO, C., María en la obra de la salvación, Madrid: BAC, 1974, 62-63.

${ }^{31}$ Ibidem, 63-64. Convém deixar claro que o Concilio na Lumen Gentium 54 em si permaneceu neutro em relação às duas tendências da mariologia católica contemporânea. Cf. POZO, C., op. cit. 105-108.

${ }^{32}$ Cf. Lumen Gentium, 59.
} 
serva do Senhor à pessoa e obra de seu Filho, servindo sob Ele e com Ele, por graça de Deus onipotente, ao mistério da redenção.

Para participar em uma obra de tal envergadura, uma condição fundamental é a santidade, santidade que é em Maria um estado efetivo desde a sua concepção: "a Virgem foi preservada e foi imune de toda mancha da culpa original" proclama o dogma. O extraordinário na apresentação da imaculada conceição pelo Vaticano II é que o Concílio não se restringe somente à noção de isenção do pecado, mas recupera e assimila uma noção que era cara aos Santos Padres, ou seja, a noção de santidade de Maria ao dizer no $\mathrm{n}^{\circ} 56$ que a Mãe de Deus é toda santa. A expressão "toda santa" corresponde ao termo grego "panagia" ou ao termo latino santissimus, ou seja, Maria é santíssima, e é isso que o dogma da Imaculada Conceição no fundo quer afirmar, a saber, que Maria é santa desde o início de sua concepção, donde a noção de isenção do pecado original. Ao integrar a expressão "toda santa" na explicitação do dogma da Imaculada Conceição, o Concílio demonstrou também a sua sensibilidade ecumênica, pois na igreja oriental em vez do conceito de isenção do pecado, usa-se o conceito de "panagia". Com isso em relação ao dogma da Imaculada Conceição, o Concílio Vaticano II realizou uma síntese extraordinária, integrando a riqueza doutrinal de dois milênios e que vem fazer jus mesmo àqueles que no passado ${ }^{33}$, antes da proclamação oficial do dogma, tiveram dificuldades de aceitarem a noção de isenção de pecado, como, Boaventura, Alberto Magno e Tomás de Aquino ${ }^{34}$ entre outros, mas que, no entanto, sempre reconheceram a suma santidade de Maria. ${ }^{35}$

${ }^{33}$ Cf. OTT, Ludwig. Manual de Teología Dogmática. Barcelona: Herder, 1997, p. 317.

${ }^{34}$ S. Th. III. Q. 27, a. 2, sol. 2: “dicendum quod, si nunquam anima Beatae Virginis fuisset contagis originalis peccati inquinata, hoc derogaret dignitati Christi secundum quam est universalis omnium Salvator" (deve-se dizer que se a alma da Bem-aventurada Virgem não tivesse sido nunca manchada pela transmissão do pecado original, seria uma diminuição da dignidade de Cristo, que é o Salvador universal de todos). A dificuldade de Tomás de Aquino foi a de conciliar a imaculada conceição com o dogma da universalidade da redenção por Cristo. A solução encontrada pelo teólogo franciscano Guilherme de Ware e, sobretudo por seu discípulo Duns Escoto (...1308), foi a de introduzir conceito como praeredemptio, que conseguiu harmonizar a verdade de que Maria também teve necessidade de ser redimida, mas ela o foi antecipadamente, preventivamente. Em vista de sua missão ela foi preventivamente preservada da mancha do pecado original. Segundo Escoto, a preservação do pecado original é maneira mais perfeita de redenção, de modo que foi conveniente que Cristo redimisse a sua Mãe desta maneira.

${ }^{35} \mathrm{~S}$ Th. III. Q. 27, a. 2, sol. 2: "Et ideo sub Christo, qui salvari non indiguit, tanquam universalis Salvator, maxima fuit Beatae Virginis puritas" (Por isso, a pureza da Bem-aventurada Virgem foi a maior de todas, abaixo de Cristo, que não tinha necessidade de ser salvo por ser 


\section{Doutrina marial em harmonia com a Tradição e as fontes patrís- ticas - o paralelismo entre Maria e Eva}

O Concílio Vaticano II assumiu a corrente patrística de renovação que estava em andamento na época como a publicação da coleção Sources Chrétiènnes e de outras obras, que sinalizavam a grande fecundidade desse campo da pesquisa, que não significou somente uma volta ao passado, mas se tratou de compreender, como a nossa fé, no que se refere à Mãe de Deus, fez parte da fé dos Padres, e procedendo assim podemos encontrar nos escritos patrísticos um verdadeiro tesouro de teologia marial. ${ }^{36}$

Neste sentido, a síntese doutrinal do cap. VIII da Lumen Gentium no que se refere à associação de Maria ao Cristo, retoma a reflexão patrística sobre o paralelo Maria e Eva, em que Maria é agora a Nova Eva associado ao Novo Adão na luta contra o pecado. Assim como o Novo Adão, em nenhum momento Maria foi conivente com o pecado e a injustiça, sendo, portanto, a Imaculada Conceição. O paralelismo Maria/Eva constitui, na realidade, importante teologúmeno, cuja primeira apresentação nos é dada pelo apologista Justino (165 d.C.), tendo assim inaugurado, ocasionalmente, a temática que, mais tarde, através de santo Irineu (202 d.C.) recebeu um estatuto teológico. ${ }^{37}$

A importância desse tema é dupla, a saber: primeiramente como uma etapa do desenvolvimento da doutrina marial, e em seguida, o que é mais importante ainda, a integração de Maria na história da salvação. ${ }^{38}$

No seu diálogo com o judeu Trifão, Justino aplica o Salmo 21 a Cristo, afirmando que ele é Filho de Deus antes de toda a Criação, e que "se é por intermédio de uma virgem que ele se fez homem, foi no desejo de que, pela mesma via em que a desobediência, oriunda da serpente, teve o seu princípio,

o salvador universal).

${ }^{36}$ LAURENTIN, René. Mutter Jesu-Mutter der Menschen. Zum Verständnis der marianischen Lehre nach dem Konzil. Limburg an der Lahn: Verlag Limburg, 1967, p. 74-75.

${ }^{37}$ Cf. MÜLlER, Alois, Ecclesia - Maria. Die Einheit Marias und der Kirche, $2^{\mathrm{a}}$ ed., Freiburg in der Schweiz: Universitäts Verlag, 1955, 48.

${ }^{38}$ Cf. LAURENTIN, R., Court traité sur la Vierge Marie, 43. Essa comparação entre Maria e Eva revela uma característica muito interessante da maneira de pensar dos Padres. Ibidem., 43: "O pensamento dos Padres, mais intuitivo que dedutivo, mais simbólico que lógico, evolui não em forma de silogismos, mas pela confrontação de teses e símbolos carregados de verdade. Discernem entre Eva e Maria um paralelo e um contraste. Paralelo de situação, pois nos dois casos, uma mulher, uma virgem. Faz um ato moral que implica a salvação de toda a humanidade. Contraste de engajamento, pois Eva desafia Deus e desobedece, enquanto Maria acredita e obedece. O resultado é de um lado o pecado e a morte, de outro lado a salvação e a vida". 
encontre igualmente a solução. Com efeito, Eva, sendo virgem e incorrupta, deu luz à desobediência e à morte pela palavra saída da boca da serpente. Maria, a Virgem, ao contrário, concebeu fé e alegria, no momento em que o anjo Gabriel lhe deu a boa notícia de que o Espírito do Senhor viria sobre ela e o poder do Altíssimo a cobriria com sua sombra, de modo que o Santo, que seria dado à luz por ela, seria Filho de Deus, respondeu: 'faça-se em mim segundo tua palavra'. E dela nasceu aquele sobre quem, como temos demonstrado, tantas passagens das Escrituras falam, através do qual Deus destrói a serpente, os anjos e os homens que se assemelham a ela; libertando, porém, da morte os que se convertem das más obras e nele crêem". ${ }^{39}$

Segundo o contexto destas palavras de Justino, não se trata primeiramente de explicação da relação entre Maria e Eva, e sim da aplicação do S1 21 a Cristo. ${ }^{40}$ Mas na vitalidade do seu pensamento, as ideias lhe vêm uma atrás das outras, sem ordem rígida, e nessa cascata um ensinamento sobre Maria toma forma, o que, pelo visto, lhe é familiar. Nesse ensinamento é desenvolvido o pensamento da recirculação, a saber, do fato de que pelo mesmo caminho que a desobediência começou, foi ela novamente desfeita, remetendo-nos assim a Rm 5,19, embora se trate ali do paralelo Adão/Cristo. Aqui, embora o paralelismo entre Maria e Eva não seja muito feliz, o seu pensamento é claro: a virgem Eva e a Virgem Maria se encontram uma diante da outra. Enquanto uma produz a desobediência pela palavra do anjo mau, a outra, pela palavra do anjo bom produz a obediência na fé e na alegria; Eva acolhe então a palavra do diabo, e Maria concebe o Logos de Deus. ${ }^{41}$

A esse tema esboçado por Justino, santo Irineu de Lion procurou dar relevo impressionante, pois para ele o paralelo Maria/Eva é peça integrante de sua teologia da salvação, na base da qual se encontra a ideia de que o plano salvifico de Deus não é um remendo da primeira obra, mas uma retomada pelo princípio, uma regeneração pela cabeça, enfim, a recapitulação em Cristo. Aparece também a mesma idéia da recirculação (recirculatio): o Cristo retoma Adão; a cruz, a árvore da queda, e nesse conjunto, Maria que retoma Eva, ocupa lugar

\footnotetext{
${ }^{39}$ Dial. C. Tryph. 100; (PG 6, 712).

${ }^{40}$ Cf. MÜLLER, A., Ecclesia - Maria. Die Einheit Marias und der Kirche,49.

${ }^{41}$ Ibidem,49-50. Essa confrontação Eva-Maria é vista como uma simples extensão da antítese Adão-Cristo. A questão que se propõe é a de saber se JUSTINO faz intencionalmente referência ao Protoevangelho e se é dali que ele tira o paralelo Eva/Maria. Uma coisa, no entanto, parece certa, a saber, JUSTINO vê no Filho da Virgem Maria, que destrói o demônio e seu sangue, a realização do Protoevangelho. Id., 50-51.
} 
de primeiro plano. ${ }^{42} \mathrm{O}$ princípio fundamental é o desenvolvimento, dirigido por Deus, de toda a história do mundo para a unificação da criação com o Criador, de acordo como se consumou em Cristo, ${ }^{43}$ o novo Adão, o perfeito, a cabeça da humanidade, por ele e nele regenerada. Por sua encarnação, o Cristo recapitula em si a longa série de homens que estavam à procura da salvação, restaurando neles a imagem e a semelhança com o Pai. ${ }^{44}$ Nesta monumental epopeia da salvação, da restauração, da recapitulação, operada pelo Filho de Deus, Irineu apresenta o paralelo entre as duas virgens, Eva e Maria.

Ao dizer que "o inimigo não teria sido vencido convenientemente se seu vencedor não fosse homem nascido de mulher, uma vez que no começo foi através da mulher que ele ganhou domínio sobre o homem, tornando-se seu inimigo", ${ }^{45}$ Irineu apresenta um pensamento que já se esboçava em Justino, a saber, "per feminam mors, per feminam vita", através da mulher veio a morte, através da mulher veio a vida. Nesse sentido Maria é vista como a recapitulação da "mulher" Eva, assim como Cristo é a da humanidade ou de Adão, ${ }^{46}$ o que é dito de maneira mais expressiva ainda no seguinte texto: "E como aquela... desobediente se tornou causa de morte para si e para o gênero humano, assim Maria, obediente, se tornou para si e para todo o gênero humano a causa da salvação... Assim as amarras da Eva desobediente foram desatadas através da obediência de Maria, pois o que a Eva virgem ligou pela incredulidade, a Virgem Maria desligou pela fé". ${ }^{47}$

Irineu apresenta o paralelo entre Maria e Eva nos seguintes elementos:

1. Eva abriu à Serpente o caminho em direção da humanidade trazendo assim a morte-Maria deu à luz Cristo, que esmagou a cabeça da serpente, e trouxe assim a vida.

2. A atitude interior de Eva foi a incredulidade contra Deus, donde a sua desobediência. A atitude interior de Maria foi de fé, donde a sua obediência.

\footnotetext{
${ }^{42}$ Cf. LAURENTIN, R., op. cit., 43; DE FIORES, in: Nuovo Dizionario de Mariologia, 1387.

${ }^{43}$ Cf. MÜLLER, A. op. cit., Adv. haer. 4, 20; (PG 7, 1034B).

${ }^{44}$ Cf. DE FIORES, S., op. cit., 1387.

${ }^{45} \mathrm{Cf}$. PG 7,1179 AB: "Pois o inimigo não teria sido vencido de uma maneira justa (adequada), se não viesse da mulher aquele que venceu, pois por uma mulher o homem foi vencido, no inicio, fazendo-se a si mesmo inimigo para o homem".

${ }^{46}$ Cf PG 7, 964B.

${ }^{47}$ Cf. PG 7, 959-960.
} 
3. No momento da queda, Eva tinha marido, mas era virgem. Maria tinha igualmente marido e foi sempre virgem. ${ }^{48}$

A idéia que atravessa todos esses argumentos é a da recapitulação: assim como a condenação, também a salvação da humanidade veio pelo mesmo caminho, mas desta vez pela obediência da mulher que deu à luz o Salvador. Eva é ainda mãe da vida (Gn 3,20), e mãe da morte (PG 7, 1179AB). O paralelo Maria/Eva compensa assim o aspecto luminoso de Maria, e possibilita a polaridade do arquétipo nela.

O que a reflexão de santo Irineu revela é que Maria, recapitulando Eva, a elevou, a redimiu da maldição primordial. A idéia de redenção é usada aqui com precauções, mas é, no entanto, significativa do ponto de vista psicológico, pois, em Maria, Eva não foi recalcada, e sim elevada e conduzida à mutação, ao positivo. No círculo interior do arquétipo, é fundamental que o aspecto negativo se transforme em positivo, ou que contribua para a mutação positiva do feminino. Esse aspecto de intercessão, de mediação de Maria em relação a Eva, a "mãe de todos os viventes", santo Irineu o exprimiu pelo termo "advogada", "defensora" (Advocata). ${ }^{49} \mathrm{O}$ título evoca, evidentemente, no contexto do texto, um tema distinto, a saber, o de Maria que obedece, em contraposição a Eva que desobedece. Não se trata de intercessão no sentido próprio da palavra, ou que Maria tenha feito valer alguns méritos a favor de Eva. Maria, fazendo o contrário do que fez Eva, destruiu deste modo a sua obra, e conseguiu retificar as funestas conseqüências da desobediência de Eva. A alusão é simplesmente à cena da Anunciação, onde o "sim" de Maria possibilitou a vinda do Cristo e, com ele, da salvação. A obediência de Maria pelo seu "sim" destruiu a ação perniciosa de Eva. ${ }^{50}$ Embora a redenção seja obra única de Cristo, contudo no conjunto do mistério salvífico cada elemento que constitui o todo tem o seu significado soteriológico, emanado, é claro, da única redenção operada por Cristo. Maria tem, pois, nesse sentido, um significado soteriológico em relação a Eva, que era esboço antropológico da mulher. Maria é a restauração e aperfeiçoamento desse projeto que havia falido. ${ }^{51}$

\footnotetext{
${ }^{48}$ Cf. MÜLLER, A., op. cit, 62.

${ }^{49}$ Cf. PG 7,1175B: "E ainda que aquela desobedeceu a Deus, esta achou por bem obedecer a Deus, para que a virgem Maria fosse a advogada da virgem Eva".

${ }^{50}$ Cf. POZO, C., María en la obra de la salvación; cf. tb. ALDAMA, J. A., María en la Patrística de los siglos I y II,s 287ss.

${ }^{51}$ Cf. LAURENTIN, R., in Nuovo Dizionario de Mariologia, 1020.
} 
O paralelismo Eva-Maria, em Justino e Irineu, representa, em certo sentido, um prelúdio da denominação de Maria como a "Nova Eva", título esse que, na verdade, foi o fundo implícito, não formulado da antítese Eva-Maria. ${ }^{52}$ Com efeito, na continuação da evolução teológica, "lenta e progressivamente, se reconhecerão, em Maria, todos os aspectos do papel de Eva. Desde 377, Epifânio vê nela a 'Mãe dos viventes', segundo a fórmula de Gn 3,20. E é somente durante a segunda metade do séc. XIII que será posto à luz o último traço do paralelo, a saber, Maria, 'auxiliar semelhante' do novo Adão, segundo a fórmula de Gn $2,18 " .{ }^{33}$

\section{Conclusão}

Para levar adiante o impulso dado pelo Concílio Vaticano II para uma teologia marial renovada, Paulo VI, por sua vez, contribuiu para a promoção do culto marial, publicou em 1974 a Exortação Apostólica Marialis Cultus ${ }^{54}$, que pela qualidade do tratamento, riqueza teológica e pastoral, constitui o documento mariano mais importante em seguida ao capítulo VIII da Lumen Gentium $^{55}$, em que destaca que uma das causas da crise mariana contemporânea estaria num tipo de "ausência de sentido", não que Maria como tal não tivesse sentido, mas como consequência de um "desconcerto entre certos dados deste culto e as hodiernas concepções antropológicas e a realidade psicossociológica, profundamente mudada, em que os homens do nosso tempo vivem e operam". ${ }^{56}$

Existe a procura de significação do culto marial que venha ao encontro dessas mudanças, e as respectivas aspirações disso decorrentes. A Marialis cultus indica então a visão antropológica para que Maria possa ser reconhecida no seu significado para o homem e a mulher de hoje: "Desejamos acentuar que a nossa época, não diversamente das precedentes, é chamada a aquilatar

\footnotetext{
${ }^{52} \mathrm{Cf}$. POZO, Candido, op. cit. 32-33. Interessante é constatar que originalmente a denominação "Nova Eva" não foi criada para Maria, e sim para a mulher de Jó, que o instigou para o pecado. Cf. LAURENTIN, R., in: Nuovo Dizionario de Mariologia, 1020; S. AGOSTINHO, De urbis excidio 3; Pl 40, 719.

${ }^{53}$ LAURENTIN, R. Court traité sur la Vierge Marie, 44.

${ }^{54}$ PAULO VI. Marialis Cultus. Exortação Apostólica para a reta ordenação e desenvolvimento do culto à Bem-aventurada Virgem Maria, 1974.

${ }^{55}$ Cf. DE FIORES, S., Maria, presenza viva nel popolo di Dio, 101.

${ }^{56}$ Marialis Cultus, 34.
} 
o próprio conhecimento da realidade com a palavra de Deus e, confrontar as suas concepções antropológicas e os problemas que daí derivam com a figura da Virgem Maria, conforme é proposta no Evangelho.

Desse modo, a leitura das divinas Escrituras, feita sob o influxo do Espírito Santo e tendo presente as aquisições das ciências humanas e as várias situações do mundo contemporâneo, levará a descobrir que Maria pode bem ser tomada como modelo naquilo por que anelam os homens do nosso tempo". ${ }^{57}$

Isto significa que os homens de hoje não se contentam com apelar somente à história da salvação. De fato, Deus é vontade e quer salvar o homem, mas é também sabedoria, e se ele deseja algo para o homem, é porque esse algo tem significado, pois Deus quis que Maria tivesse lugar especial na história da salvação.

Do impulso dado pelo Concílio Vaticano II para a promoção do culto mariano, tivemos, além da Marialis Cultus de Paulo VI, a Carta Encíclica do Papa João Paulo II, a Redemptoris Mater ${ }^{58}$, que acentua a presença de Maria na vida da Igreja como aquela que como peregrina, caminha junto com o povo de Deus.

$\mathrm{Na}$ América Latina também, a Conferência de Puebla ${ }^{59}$ apresentou uma mariologia vigorosa, confirmada depois pela Conferência de Aparecida ${ }^{60}$.

\section{Referências bibliográficas}

BOFF Clodovis. Introdução à Mariologia. Petrópolis: Vozes, 2004. . Mariologia Social. O significado da Virgem para a Sociedade. São Paulo: Paulus, 2006.

BROWN, Raymond E. (Org.). Maria no Novo Testamento. São Paulo: Paulinas, 1985.

COURTH, Franz (Org.). Texte zur Theologie - Dogmatik - Mariologie. Graz Wien Köln: Styria, 1991.

\footnotetext{
${ }^{57}$ Ibidem, 37.

${ }^{58}$ JOÃO PAULO II. Carta Encíclica Redemptoris Mater, 1987.

${ }^{59}$ PUEBLA. Evangelização no presente e no futuro da América Latina, 1979.

${ }^{60}$ APARECIDA. Texto conclusivo da V Conferência Geral do Episcopado Latino-Americano e do Caribe. Aparecida, 2007.
} 
DENZINGER, Heinrich; HÜNERMANN, Peter. Compêndio dos símbolos, definições e declarações de fé e moral. São Paulo: Paulinas/Loyola, 2007.

Documento de Aparecida. Texto conclusivo da V Conferência Geral do Episcopado Latino-Americano e do Caribe. 13-31 de maio de 2007. São Paulo: Edições CNBB/Paulus/Paulinas, 2007.

DE FIORES, Stefano; MEO, Salvatore (Org.). Nuovo Dizionario di Mariologia. Roma: Paulinas, 1985.

DE FIORES, Stefano; MEO, Salvatore (Org.). Dicionário de Mariologia. São Paulo: Paulus, 1995.

GEBARA, Ivone; BINGEMER, Maria Clara Lucheti. Maria, Mãe de Deus e Mãe dos pobres. Um ensaio a partir da mulher e da América Latina. Petrópolis: Vozes, 1987.

JOÃO PAULO II. Carta Encíclica Redemptoris Mater, 1987.

LAURENTIN, René. Court traité sur la Vierge Marie. Cinquième édition, refondue à la suite du Concile. Paris : Lethielleux, 1967.

LAURENTIN, René. Mutter Jesu-Mutter der Menschen. Zum Verständnis der marianischen Lehre nach dem Konzil. Limburg an der Lahn: Verlag Limburg, 1967.

LIBANIO, João Batista. Concílio Vaticano II. Em busca de uma primeira compreensão. São Paulo: Loyola, 2005.

MÜLLER, Alois. O lugar de Maria e sua cooperação no evento Cristo. In: Mysterium Salutis III/7, 71-181, Petrópolis: Vozes, 1974.

MÜLLER, Alois, Ecclesia - Maria. Die Einheit Marias und der Kirche, 2a ed., Freiburg in der Schweiz: Universitäts Verlag, 1955.

MURAD, Irmão Afonso. Maria, Toda de Deus e tão Humana. São Paulo/ Valencia: Paulinas/Siquem, 2004.

PAULO VI. Marialis Cultus. Exortação Apostólica para a reta ordenação e desenvolvimento do culto à Bem-aventurada Virgem Maria, 1974.

POZO, Cándido SJ. María en la obra de la salvación. Madrid: BAC, 1974.

POZO, Cándido SJ. María, nueva Eva. Madrid: BAC, 2005. 
PUEBLA. Evangelização no presente e no futuro da América Latina, 1979. VATICANO II. Lumen Gentium 52-69.

Pedro K. Iwashita CSSp. Doutor em Teologia pela Universidade de Fribourg, Suiça Professor da Faculdade de Teologia na PUC/SP São Paulo / SP - Brasil E-mail: iwashita@uninet.com.br

Recebido em: 25/07/14 Aprovado em: 10/10/14 